\title{
ARTICLE
}

\section{Forgiveness and the Repairing of Epistemic Trust}

\author{
Adam Green \\ University of Oklahoma, Norman, Oklahoma, USA \\ Email: greenab3@gmail.com
}

(Received 10 March 2021; revised 1 June 2021; accepted 11 June 2021)

\begin{abstract}
The epistemic relevance of forgiveness has been neglected by both the discussion of forgiveness in moral psychology and by social epistemology generally. Moral psychology fails to account for the forgiveness of epistemic wrongs and for the way that wrongs in general have epistemic implications. Social epistemology, for its part, neglects the way that epistemic trust is not only conferred but repaired. In this essay, I show that the repair of epistemic trust through forgiveness is necessary to the economy of knowledge for fallible persons like us. Despite the fact that forgiveness is never included on lists of important intellectual virtues or epistemic activities, it is vital to our lives as social knowers. Likewise, an account of forgiveness that neglects its epistemic dimension is importantly incomplete.
\end{abstract}

Keywords: Forgiveness; trust; epistemic injustice

\section{Introduction}

In the relationships we value, we are used to the idea that sometimes someone we trust and are committed to doing life with will profoundly disappoint. Someone might be worthy, in general, of the trust we place in them, and yet be such that good relations demand periodic repair. In fact, the need for re-attunement and repair is a fixture of a relationship of any depth. Yet, one sees no intimation of this relational reality in social epistemology. Recent work in epistemology has shown a sensitivity for the need of a "non-ideal epistemology" analogous to non-ideal political theory. This has led primarily to a focus on intellectual vices, perverse epistemic practices, and epistemic oppression (cf. Barker et al. 2018). What prosocial practices and virtues might be required as responses to the non-ideal needs further development. In this essay, we will be concerned with one such practice and virtue, namely, forgiveness and the disposition to forgive. ${ }^{1}$

\section{Forgiveness in the broad}

It is not possible in this article to do justice to the live debates on forgiveness. Yet, giving an account of epistemic forgiveness is most usefully done against the backdrop of a clear

\footnotetext{
${ }^{1}$ There have been several recent articles on epistemic excuses (Greco 2019; Littlejohn Forthcoming). Excusing and forgiving play similar though differentiable roles in moral and legal discourse (e.g. Pettigrove 2007). If excuses are a legitimate subject of epistemic inquiry, then so too should forgiveness be. terms of the Creative Commons Attribution licence (https://creativecommons.org/licenses/by/4.0/), which permits unrestricted re-use, distribution, and reproduction in any medium, provided the original work is properly cited.
} 
picture of what forgiveness is, and so it will be helpful to articulate that picture explicitly.

In the interests of space, we will begin by piggybacking on an essay by Roberts (1995) on the character trait of being a forgiving person, what he calls "forgivingness." As is well known, Roberts has it that emotions are a kind of "seeing as," akin to the way the same drawing might appear to one as a duck or a rabbit depending on how one attends to it. An emotion is a "concern-based construal," a way of cognitively relating to the object as relevant to one's values in a particular way. For Roberts, forgiveness involves moving from an anger-based construal of the wrongdoer to a more benevolent one.

Forgivingness is the disposition to abort one's anger (or altogether to miss getting angry) at persons one takes to have wronged one culpably, by seeing them in the benevolent terms provided by reasons characteristic of forgiving. (Roberts 1995: 290)

When the victim succeeds in forgiving his offender, he does not see her, in that specially vivid and concern-based way that constitutes anger, in terms of his beliefs about her offense against him; instead he sees her in other, more benevolent terms that derive from his reasons for forgiving her. (Roberts 1995: 293)

The importance of being a forgiving person, for Roberts, is that viewing another person as a wrongdoer, continuing to construe him through the eyes of anger, precludes the ability to relate to the other person as a person, that is, someone with strengths and weaknesses, successes and failures, someone capable of wrongs but also capable of much more. This dynamic explains why we do and at least sometimes should find genuine repentance moving and why appreciating the other's story from their perspective might move us to forgive and not just excuse.

I propose, then, that the emotion "overcome" in forgiveness is anger, and that the facet of anger that makes it important sometimes to overcome it, even in its morally purest forms, is the "view" of the offender as bad, alien, guilty, worthy of suffering, unwelcome, offensive, an enemy, etc. (Roberts 1995: 293)

Repentance as a reason for forgiving suggests that the aim of reconciliation is basic to forgiveness, a return to the status of being fellows. (Roberts 1995: 294)

An important dimension of the virtue will be an ability and disposition to take the viewpoint of sufferers, in particular of sufferers who have offended against us. (Roberts 1995: 297)

Roberts does not think that this shift in construal is just something that happens to us. We can intentionally foster a different way of emotionally attending to the other person.

Forgivingness consists in sensitivity to such anger-reducing considerations; self-management in forgiveness consists in exploiting such considerations with a view to reducing one's anger. (Roberts 1995: 293)

Thus forgivingness seems to involve a certain amount of self-awareness and selfmanagement skill. She has to "know," for example, that her anger can be reduced by finding excuses for her offender, by considering her own moral resemblance to the offender, by focusing compassionately on the offender's misery, by 
remembering her own indebtedness; and she has to be somewhat practiced in turning her mind to these considerations. (Roberts 1995: 303)

Roberts is concerned with describing a virtuous disposition to forgive. Suppose that it is possible for the virtuous to become the kind of people who see those who commit wrongs against them in benevolent terms. One might accept that while doubting that such benevolent construing is strictly necessary for forgiveness. It is instructive, though, that a similar thought shows up in other treatments of forgiveness, even if not in Roberts' terms.

\section{Consider, for instance, this passage from Griswold (2007).}

For her part, the victim must re-frame both her view of the offender and her view of herself. ... Re-framing your perspective on the offender, and eventually yourself, means that your resentful "stories" ... must be revised. Furthermore, you must re-frame your view of yourself, in part insofar as your self-definition is affected by your oppositional relation to enemies or oppressors. (Griswold 2007: 183-4)

This is supposed to be a point that is generally applicable. To hold a wrong against someone involves thinking of someone in certain affectively laden ways, which then can frame how one relates to them generally. To forgive someone requires re-framing how one thinks about the other person. This brings us to a point well worth highlighting for the purposes of this paper, namely, that what Roberts and Griswold here point to without explicitly noting it is that there is an epistemic dimension of forgiveness. Forgiveness requires a change in the affectively loaded way one represents the wrongdoer to oneself and perhaps also to others. ${ }^{2}$

Within the literature, there are various thoughts on what the functional role of forgiveness might be within one's psychic economy and whether it is unique either in its ends or its means to its ends. Yet, there is a fair amount of agreement that forgiveness at least moderates resentment, that it changes either the victim's right to blame the wrongdoer or their reasonable exercise of that right, and that it promotes reconciliation other things being equal.

Resentment can mean different things in the forgiveness literature, ${ }^{3}$ but it can be taken as a useful proxy for the suite of negative reactive attitudes one holds towards a wrongdoer in virtue of a wrong. Taken as a genus in this way, resentment is a

\footnotetext{
${ }^{2}$ Here we can see why a criticism of Griswold on exactly this point by Wolterstorff misses the point. Wolterstorff (2013: 421) says, "More relevant, however, is what Griswold says the victim must do. She must re-frame her view of the offender and of herself. I regard this as much too intellectual a view of the matter. I hold that forgiveness involves not just how one views the offender but, more importantly, how one treats the offender, how one engages her". The point is not intellectual so much as epistemic. The way one thinks about a person sets the stage for how one will treat her.

${ }^{3}$ To take a few examples of the diverse treatments of resentment in the literature, Urban Walker (2013: 503) thinks resentment is our reactive attitude to norm violation. Hieronymi (2001) takes it to be an affective response, typically on the part of the victim, to the implicit claim that it is okay for the wrongdoer to treat the victim the way he did. These are thicker descriptions that would significantly restrict the range of objects the emotion can take. Roberts in choosing anger as his focus over resentment takes resentment to be a form of anger that is brooding and defensive, that is, an instance of anger with a particular phenomenal character and pattern of manifestation (Roberts 1995: 291). Strawson (1968: 74ff) held that resentment is non-moral anger, which is obviously inconsistent with the thicker descriptions of resentment above and may also be inconsistent with the claim that it has a particular phenomenal signature. For a more exhaustive if brief list, see Hughes and Warmke (2017: section 5.1).
} 
personally invested emotional disapproval of the other person. Suffering a wrong can provoke in one a disinclination to interact with the other person, a negative characterological assessment of the wrongdoer, a hostile and uncharitable interpretation of actions outside of the wrong done, a vested interest in others coming to see the wrongdoer in the same negative light, and a disgust at the wrongdoer's own attitude towards the event. The emotional force of any of these attitudes towards the wrongdoer could be expressed in the language of resentment. One does not simply disagree or disinterestedly disapprove. A sense of being wronged, rather, often comes with a disapproval that one either would not have or would not feel so acutely were it not for the wrong at issue.

One could hold that a true act of forgiveness would involve forswearing or giving up resentment towards the wrongdoer in all of its manifestations. ${ }^{4}$ But that is the extreme. It seems reasonable to allow that someone has successfully engaged in an act of forgiveness even if one involuntarily experiences negative appraisals of the other person, if, for instance, these emotions are less than they may have been and one resists the temptation to stoke one's resentment against the other. ${ }^{5}$ What seems even more clear, however, is that if one's feelings of resentment are unaffected by a putative act of forgiveness that is reason to think that the act was unsuccessful. Someone who does nothing about a desire to see the wrongdoer suffer intensely, no matter what else she may do, does not manage to forgive him. Hence, forgiveness moderates resentment.

Resentment and blame are related. If one resents another person for an action that is not blameworthy, it becomes harder to see how that resentment could be justified. At the least, resentment in the absence of blameworthiness does not seem like a justified moral emotion. Likewise, even though it is possible to imagine dispassionate blame, it is hard to imagine the emotional tenor of blame as we typically experience it without

\footnotetext{
${ }^{4}$ Even views that are this extreme do not necessarily claim that one must overcome one's resentment completely at a moment. Griswold (2007: 53-8), for instance, thinks that forgiveness requires forswearing revenge, moderating resentment, and committing to the eventual overcoming of lingering resentment.

${ }^{5}$ Some seem dubious that overcoming resentment should be built into an analysis of forgiveness. Wettstein, for example, emphasizes the way that forgiveness often is extended easily or because one's resentment just melts away in the face of a genuine apology (cf. Wettstein 2010: 450, 453). He thinks that overemphasizing the effortful, difficult setting aside of resentment is to mischaracterize human practice and mis-describe the ideal we should aim for, namely to become someone who does not experience much resentment of others in the first place. Warmke claims that overcoming resentment cannot be what makes forgiveness normatively significant. Overcoming a private emotion, for instance, may seem insufficient to explain the import of forgiveness for the wrongdoer. Rather, what social relations one enacts through forgiveness construed as a declarative speech act are more important to him (cf. Warmke 2016: 693). Wolterstorff says, in response to Griswold's account, "Forgiveness requires letting go of one's negative feelings toward the wrongdoer; it does not require letting go of one's negative feelings toward the deed done." Thus, Wolterstorff goes as far as to suggest that at least one kind of resentment ought not be overcome! Forgiveness for him is "the enacted resolution of the victim no longer to hold against the wrongdoer what he did to one," a resolution consistent with harboring resentment against the wrongdoer to one extent or another. I find it hard to believe, however, that Wettstein, Warmke, or Wolterstorff have much reason within their perspectives to object to the claim that forgiving typically comes with a psychological change in one's disposition to resent the other which should frequently lead to fewer resentful feelings and that high levels of resentment is in general a good sign that one has not forgiven the other person. If one declares a new social reality one is unable to live with or enacts a resolution one is unable to follow, then what good is the declaration or the resolution? Thus, moderating at least strong resentment would seem to me to be a necessary precondition of Warmkian speech acts and Wolterstorff-esque resolutions. Likewise, I think character development of the sort Wettstein has in mind is a kind of diachronic moderation of one's disposition to resentment which is perfectly consistent with synchronic efforts to moderate particular resentments. Indeed, the latter might be important to developing the former.
} 
invoking some form of resentment. ${ }^{6}$ Scanlon defines blame in terms of judging another person to have damaged his or her relationship with oneself and relating to the other person accordingly. ${ }^{7}$ Insofar as we are invested in our relationship and care how others treat us, then one should expect blame in Scanlon's sense to be accompanied by resentment. Whether one accepts Scanlon's definition of blame as a conceptual matter or not, he is pointing out our tendency to think of blame within the context of our relationships. In fact, one might think that the interpersonal point of expressions of blame is to give voice to one's resentment in a way apt for producing a matched emotion of remorse in the wrongdoer. ${ }^{8}$

Moderating one's feelings of resentment gives one the psychological space to relate differently to blame. Yet, how exactly one relates anew to blame seems to depend on the context of forgiveness. In the paradigmatic interactive case, a wrongdoer owns their guilt, expresses contrition, and makes a good faith commitment to do better going forward. The wrongdoer in this case enacts the aptness of blame. Given that blame has found its mark, continued blame behavior on the part of the victim can strike one as a refusal to accept the repentance of the wrongdoer. Forgiveness, in this context, has to do with accepting the relational gambit of the wrongdoer. Forgiving a good faith apology creates the social expectation that one will no longer engage in blaming for this event.

There are, of course, other cases and scouting the terrain a bit will prove helpful when we turn to specifically epistemic forgiveness in the next section. The wrongdoer might disagree about the nature of the wrong, about the assessment of blame, and about what future changes are appropriate. Thus, a wrongdoer might only approximate the ideal request for forgiveness. And, of course, they might not make the request at all in which case some might hold that forgiveness either is not possible or not appropriate. ${ }^{9}$ Nonetheless, what is certainly clear is that renegotiating blame is possible and sometimes appropriate outside of the paradigmatic interpersonal case.

\footnotetext{
${ }^{6}$ One might doubt this. For instance, Brown remarks, "blame needn't always take the form of resentment and guilt. For instance, I might blame a friend who's betrayed me by deciding to continue the relationship with feelings of loss and disappointment rather than indignation and resentment" (Brown 2020: 390; also 402). Resentment, here, however is being used in a narrow sense, and if the feelings of loss and disappointment referenced are not informed by a personally invested disapproval of the other person, then it is not clear to me that we are talking about blame. It is possible, for instance, to feel loss and disappointment without disapproval or personal investment when two people simply grow apart, but one would not typically describe one's emotions about such a development with the language of blame.

7"[T] o claim that a person is blameworthy for an action is to claim that the action shows something about the agent's attitudes toward others that impairs the relations that others can have with him or her. To blame a person is to judge him or her to be blameworthy and to take your relationship with him or her to be modified in a way that this judgment of impaired relations holds to be appropriate" (Scanlon 2008: 128-9).

${ }^{8}$ Fricker says of "communicative blame" that "the illocutionary point of any performance of communicative blame is to inspire remorse in the wrongdoer, where remorse is understood as a pained moral perception of the wrong one has done" (Fricker 2016: 167). If one thinks of forgiveness as involving a shift in how one sees the wrongdoer, then Fricker's emphasis on "pained moral perception" as important to remorse is striking. It suggests that both the wrongdoer and the victim should experience a change in how they construe the situation, a "seeing as" change, for a forgiving interaction to work as it should.

${ }^{9}$ Wolterstorff is well known for opposing the idea of forgiving the unrepentant (Wolterstorff 2011; cf. Wright 2019). Likewise, Fricker warns that "gifted forgiveness," that is unconditional forgiveness, is peculiarly prone to "deterioration into forms of moral dogmatism and manipulation" (Fricker 2018: 167) by being unfair to the wrongdoer! How so? Gifted forgiveness shuts down the space for dialogue about the nature of the wrong done. The victim can end up using their supposed magnanimity in the face of a wrong to impose their viewpoint on the other.
} 
Most straightforwardly, one might decide to accept a real but less than ideal apology as good enough. One might, in effect, take a satisficing approach to the repentance of the other, perhaps factoring in the importance of the relationship, the triviality of the wrong, and the other's past track record. To even the unapologetic wrongdoer whose moral trajectory nonetheless is in a positive moral direction, one could allow the other's track record to count towards the worthiness of the other to be forgiven or the safety of doing so. One could forswear one's right to blame such a person as a sacrificial act even though one did not, as it were, get the opportunity to have one's day in relational court. Alternatively, one might not forswear one's right to blame so much as decide not to exercise it at present in a way that ends up facilitating relational repair in the final analysis, functioning as a kind of de facto forgiveness. In these less than ideal cases, our social norms create less pressure on us to forgive and future blaming behavior does not violate our expectations as markedly.

More controversial, of course, is the malefactor who thinks they have done nothing wrong and shows no sign of changing moral course. One might be concerned, for instance, with whether forgiveness in such a situation is consistent with healthy selfrespect (cf. Murphy 1982: 505). Even in this case, one might choose to moderate one's resentment and renegotiate one's relationship to blame and, indeed, might do so as an expression of self-respect. One might, for instance, forswear one's need to engage in blaming behavior as an outlet for one's feelings of resentment or even cultivate an openness to the future repentance of the wrongdoer. One might do this in no small part because one does not want to be the kind of person who is caught up in resentment but rather someone who embraces hope for relationships like this one. One's self-respect, in effect, trumps one's desire to hold onto one's resentful feelings. ${ }^{10}$ Many would not think of such a stance as one of forgiveness, but at a minimum, there would be a family resemblance. ${ }^{11}$

The upshot of our discussion of blame is that remorse and forgiveness are ways of expressing a pro-attitude towards a relationship within the context of a relational rupture. They are ways of adopting such a pro-attitude not only despite the aptness of blame but in ways that depend on the aptness of blame. To act like a broken trust merits intentional, emotionally costly redress is to express the value of the trust that was broken, which itself goes a fair way to creating conditions for trust to flourish moving forward. Expressing blame and receiving blame can play an important role in repair, but a continued stance of blame precludes the healing of relational rupture. Thus, moderating resentment and renegotiating blame is related to promoting reconciliation. ${ }^{12}$

\footnotetext{
${ }^{10}$ Although concerned with the victim's self-respect, Murphy also thinks that forgiving someone for one's own peace of mind is not true forgiveness because its rationale is self-regarding and therefore selfish (Murphy 1982: 507; also Richards 1988: 79-80). I think it depends on the details. If the rationale is rooted in moral aspiration, for instance, the moral worth of this rationale does not disappear just because it is selfregarding, and a self-regarding moral motive does not preclude valuing others at the same time. That kind of self-regarding forgiving seems different from my trying to modify my psyche because I feel uncomfortable with the affect I'm experiencing, which does seem to lack, if not self-respect, at least an appreciation of the importance of our moral reactive attitudes. I think we lose too much of the phenomenon to be explained if we exclude all self-regarding cases.

${ }^{11}$ I find it plausible that whether one should forgive or reinstate the unrepentant is heavily dependent on how robust the social network is that would care for and protect the victim after forgiveness and that could hold the wrongdoer accountable for the victim, if not also block re-instatement in some cases (cf. Machlachlan 2008; Urban Walker 2013).

${ }^{12} \mathrm{I}$ am here focused on the interpersonal level. One should not assume that political reconciliation follows from, has the same conditions as, or is exactly analogous to reconciliation at the interpersonal level (cf. Hughes 2001).
} 
Not every wrongdoer should be re-accepted into whatever level of relationship the victim enjoyed with them prior to the wrong, and, of course, it is possible to wrong someone with whom one never had a relationship. Creating conditions friendly to reconciliation, however, even if not always achieving it, is already implicit in the moderation of resentment and renegotiation of blame. In removing obstacles to relationship and taking an interpersonal stance more conducive to interpersonal trust, forgiveness promotes reconciliation. There are many routes towards the moderating of resentment and loss of a disposition to blame the other person. Forgiveness, however, distinguishes itself partly because it is the moderating of what one takes to be legitimate resentment and not clinging to a genuine right to blame because one thinks that, to whatever extent it can be realized, it is both possible and desirable to repair the relational wound caused by the wrong. Though certainly not inevitable, this act of repair makes starting or renewing a relationship possible.

It should also be noted that successfully navigating the forgiving of a wrong can be a foundation for greater intimacy and cooperation in the future. Forgiveness, in promoting reconciliation, does not simply promote the resumption of whatever relational state was had prior to the wrong. Rather, one's relational history now includes not only something new that could push oneself and the other apart (aka the wrong committed) but also something new that militates in favor of intimacy, trust, and cooperation. To experience oneself as someone for whom the other is willing to forego rightful negative emotions in the hope of repair is to be given a gift that should cause one to think better of the giver and to value more the relationship in which it was given. ${ }^{13}$ Likewise, to experience the other as able to take ownership of their missteps, extend empathetic care towards those affected by them, and embrace corrective action has the potential to show one new grounds for trust that could even outweigh those causes for distrust latent within the wrong forgiven. Where there was no prior relationship, forgiveness can sometimes create a foundation for one. ${ }^{14}$

Thus, putting it all together, I take the following to be a good approximation of forgiveness in the broad. Forgiveness is an integrated cognitive-affective stance towards both the wrongdoer and one's feelings of resentment towards the wrongdoer that includes a commitment, even if a conditional one, to move from a stance of blame to an openness to relational repair and reconciliation as appropriate given the relational histories of the parties.

\section{Forgiveness and the epistemic}

With more of a sense of what forgiveness is in hand, we will turn to its epistemic applications after addressing a worry one might harbor about the project as a whole. In so doing, we will gain a better understanding of what repairing epistemic trust would amount to which will put us in better staid to account for epistemic forgiveness.

\footnotetext{
${ }^{13}$ As Fricker emphasizes in the context of gifted forgiveness, forgiveness offered in the absence of repentance "provides the wrongdoer with an added moral reason to repudiate her wrongs," which in turn could promote reconciliation (2018: 168).

${ }^{14}$ Although I am striking a more interpersonal note here, it is helpful to think this point through in Urban Walker's terms as well. If resentment "is anger that responds rebukingly to those believed to violate shared norms" (Urban Walker 2013: 504), then one might think that a heartfelt apology is a way of signaling clear commitment to those norms and in some circumstances can be a more useful window into the other person's commitment to the norms than when someone observes the norms with opaque motives. Remorse can, in effect, be a costly signal that leads to increased confidence in the other's norm observance going forward.
} 
One might object that there is a confusion latent within thinking of epistemic trust as the sort of thing that is a candidate for repair. Either one has reason to trust someone that $\mathrm{p}$ on an occasion or one does not. One might think that epistemic trust is not interpersonal and thickly relational in the way other kinds of trust are. Rather, one might think it a causal notion, perhaps one closely associated with the basing relation. As such, it would be just as capable of picking out tools (e.g. trusting a thermometer) and mental faculties (e.g. trusting vision) as other persons.

I readily grant that epistemic trust can be asocial. When it is another person that one is trusting epistemically, however, episodic trust is highly parasitic on trust in particular persons with whom one has a relationship or on roles that other persons occupy in situations defined by stable social norms (Green 2014). After all, if one did not already trust certain particular people in a more generalized way or trust that certain kinds of people in certain social situations were worthy of trust, then it would be difficult to find reasons that justified episodic trust events. ${ }^{15}$

In that vein, Hieronymi (2008) points out, in an essay on trust, that we are not moved to trust by general facts about the value, utility, or safety of trust in the abstract, but, interestingly, require trust to be grounded in the particular features of what (or who) we are trusting that make it trustworthy. One might think, then, that, though the three place relation of Agent-Source-Object of Trust might be the right logical formula to use in an analysis of trust, perhaps adequately capturing the phenomenon requires stressing the second variable, one's relation to the person or thing trusted. Moreover, when it comes to epistemic trust in a person, one needs to be flexible enough in how one thinks about the third place in the relation to account for not just believing what another person believes but trusting someone epistemically to give one pushback on one's beliefs, help one state one's beliefs more precisely, bolster one's confidence when one doubts one's abilities, brainstorm together, and so on. ${ }^{16}$ Distinctively epistemic trust needs to cover the various ways in which one person can rely on another when exercising one of a number of activities in the overlap of the epistemic and the social. ${ }^{17}$ In short, then, insofar as our epistemic relations with others are diachronic rather than episodic, are situated in contexts mediated by the epistemic and moral agency of the other party, or involve epistemic activities where one does some of one's thinking with the other person, it is appropriate to think of epistemic trust as the sort of thing that is an apt candidate for repair. ${ }^{18}$

\footnotetext{
${ }^{15}$ It is noteworthy to me that even in a treatment of epistemic trust quite narrowly focused on what it means for a believer to believe a particular proposition on an occasion such as McCaw's, after giving his analysis he very quickly moves to show how he could incorporate more re-occurring, diachronic social phenomena within his analysis (McCaw 2015: 425). After all, what explains episodic epistemic trust is, often enough, what particular people or types of people we have learned to trust over time.

${ }^{16}$ From the side of the person who is trusted epistemically, additionally, consider what it means to think of an epistemic partner as trustworthy or intellectually dependable (cf. Faulkner 2007; Byerly Forthcoming). Though one can speak of a testifier, for instance, being a generically trustworthy or dependable source for a particular proposition $\mathrm{x}$, trustworthiness and intellectual dependability are more naturally parsed as traits that cover a wide range of potential epistemic activities and ones that are highly responsive to relational context. Boult (2020: 7-8) similarly glosses "epistemic relationships" in an expansive rather than restricted way.

${ }^{17}$ Similarly, in this context, it is noteworthy that discussions of epistemic blame, that is blame of a distinctive epistemic kind that might be differentiated from moral blame, have tended to focus on the issue of blameworthiness for belief (cf. Nottleman 2010; McCormick 2011) and the action of blaming someone for their beliefs (cf. Brown 2020). If, however, one takes a wider view of what epistemic actions and dispositions of others are relevant to our own lives as knowers, one similarly should broaden one's views of epistemic blame.

${ }^{18}$ In defending the aptness of talking about the repair of epistemic trust between persons, I am not implying that there are no analogous situations for epistemic trust in non-agents. One might, for example,
} 
Let us turn, then, to the topic of forgiveness and the epistemic by considering some cases. These cases illustrate the way in which all acts of forgiveness have epistemic implications as well as some of the diversity of the distinctly epistemic wrongs that can become candidates for forgiveness.

General Harm, Epistemic Consequences: Madeleine, unhappy in her marriage with Martin, has an affair. Over time, she realizes that she still feels unhappy, and, after receiving some individual counseling, decides that the source of her unhappiness lies elsewhere. She ends the affair and confesses to Martin. He does not take it well. Though he loves her and wants to forgive her, he finds himself second-guessing what she tells him about her whereabouts, purchases, and feelings. He finds himself disinclined to rely on her competence and generally less inclined to prioritize their common good over his own individual projects than previously. His commitment to doing life together overrides his feelings in terms of most day to day choices, but he feels the need to maintain an epistemic perspective on that life which is in no way dependent on Madeleine's.

General Harm, Epistemic Means: Marie and Mona's mother is sick with stage four cancer. Marie, her mother's favorite child and a successful businesswoman who lives in another state, calls Mona to ask about their mother's condition. Mona, who is unemployed and living at home, feels hesitant to tell Marie the truth out of fear that Marie will swoop in and take over the care of their mother, with whom Mona has experienced an improved connection through the caretaking relationship. Mona lies, and their mother dies before Marie has the opportunity to come home and pay her last respects. Marie is deeply grieved to have not gotten a last chance to be with her mother. Though Mona does not admit to her lie, Marie correctly infers it and intuits the reason behind it.

Epistemic Injustice: Miles is dismissive of Maya in a very public setting in a way that prevents Maya from being able to express an insight that matters to her. Miles does not treat Maya's testimony as worthy of belief or her disagreement as reason to give someone intellectual pause. His dismissive behavior has the effect, at least on that occasion, of completely silencing her. He does so because he has a tendency to underestimate her competence and her intellectual seriousness due to prejudice. At some point afterwards, Miles is prompted to consider how behavior like this affects others. The epistemic wrong he has committed against Maya comes into focus, and he is stricken with feelings of remorse. At the first suitable opportunity, he expresses his regret at his actions, owns them as blameworthy, and pledges his commitment to relate to her and others differently going forward. ${ }^{19}$

In each of these three cases, we must ask how forgiveness would have to manifest itself in order to address the epistemic dimension of each case and thereby foster

trust a scientific instrument, come to doubt its reliability due to the production of anomalous results, and then have one's confidence in the instrument restored upon discovering a theoretic model that makes sense of the worrisome results.

${ }^{19}$ Fricker's (2007) landmark book Epistemic Injustice brought about an awareness in mainstream philosophy of the ways in which an injustice might be perpetrated on someone qua knower. Within Fricker's original taxonomy, the injustice in this case would be classified as a testimonial injustice, although it is important to note that silencing affects many more epistemic activities than just offering testimony. The theme of epistemic injustice as silencing is helpfully developed by Dotson (2011). 
renewed epistemic trust. The wrong in each case intersects the epistemic arena. It does so by making it harder to believe the perpetrator, by creating conditions more aversive to collaborate with them epistemically, or by otherwise negatively affecting the legitimate exercise of epistemic agency of the wronged party.

To claim that a wrong can have epistemic dimensions is not to, by itself, take a stand on whether or not there is a distinctively epistemic kind of blame. Boult (2020), for instance, argues that there is. If blame just is a modification of one's intentions, expectations, and attitudes vis-à-vis another person in virtue of their falling short of some normative ideal, then surely, so the argument goes, one can and should sometimes engage in such an adjustment in virtue of the other's falling short of an epistemic normative ideal. Epistemic blame would be a straightforward candidate for a state that could be a candidate for epistemic forgiveness. Likewise, Rettler (2017) argues that we can be blamed for our beliefs in virtue of certain types of reasons-responsiveness. If we can be blamed for our beliefs, perhaps we can be forgiven for having them.

To the extent that one thinks there is a distinct kind of epistemic blame, there should be an easy road to affirming that there is such a thing as epistemic forgiveness. Yet, my thesis is not restricted to those cases. Even if one morally blames a knower for a wrong that is distinctively epistemic in nature, then, as we shall see, the epistemic dimension of the wrong will enter into what it means to forgive in this case. Likewise, as I will show, moral wrongs routinely have epistemic dimensions that require something of us qua epistemic agents if we are to forgive them.

A wrong can cause negative emotions that radiate out from the wrong at issue to other potential objects. In fact, one might think that epistemic wrongs and the epistemic dimension of general harms are especially susceptible to having effects that are not localized solely to the particular action of the wrongdoer. The reason has to do with rational updating and our lives as social knowers.

If a non-social doxastic source did something analogous to wronging one, giving bad information or not providing the information it was supposed to, then the rational thing to do would be to become less inclined to trust that source and perhaps less trusting of sources like the failed one. If a thermometer gives the wrong reading, get a new thermometer and think twice before buying the same brand. Part of being an epistemic agent is not just accepting information at a time but accepting information in a way reflective of one's past experiences and future informational needs. Thus, discovering that a trusted source may not be trustworthy causes not only an assessment of the isolated failing but of past and potential future inquiries in light of that failing. It affects how one maps the epistemic terrain.

What goes for non-social sources applies that much more for social ones because people, unlike tools, are not only epistemically reliable or not simpliciter, they are typically only reliable sources if, among other things, one has their attention and good will. Moreover, we are not interested in the truth of just any question nor should we be. Rather, our epistemic needs and interests are shaped by our non-epistemic values and goals. Our mapping of the epistemic terrain prioritizes where we can get information on matters we care about and who will collaborate with us epistemically and otherwise on projects we are invested in.

A wrong, whether of a distinctly epistemic sort or not, signals a mis-alignment of values, goals, and intentions such that one is given reason not to rely on the other person whatever their baseline of competence. Martin, for example, might firmly believe that the affair is over and that Madeleine intends to make it work while finding it unnatural to just assume a harmony in their values and goals in the wake of the relational rupture. This feeling changes what shows up as an epistemic risk and what defeaters occur to Martin for relationally relevant beliefs. It changes what epistemic projects he 
is willing to engage in and what non-epistemic projects he will fail to commit to, in part, for epistemic reasons.

Individual victims and wrongdoers not only affect each other on an individual basis but in virtue of the social networks in which each are placed and the cognitive niches partly composed by them. When Miles is dismissive of Maya, he models an attitude towards her that could easily be picked up by others who witness the event. Miles helps to deny Maya status as a knower within and possibly even access to his social network. This diminishes Maya's exercise of her epistemic agency and jeopardizes her access to the goods, epistemic and otherwise, that this network could mediate. Maya acquires new reason to think that the social networks Miles represents will be inhospitable to, if not unavailable to, her because of, not just Miles, but people like Miles or who tolerate behavior like his.

A mere change in emotion or a mere decision to treat the other person as if the wrong were forgiven are no more sufficient for forgiveness on the epistemic level than they were for forgiveness in general. If, for instance, Marie's father tried to smooth over the wrong done her by asking Marie to take charge of the distribution of her deceased mother's things and, if, furthermore, this caused a moderating of her feelings towards Mona (e.g. by symbolizing Marie's close connection with her mother), this change is not equivalent to forgiveness. Even if it does not trace the complete path of the ill feelings engendered, forgiveness requires a cognitive-affective stance towards the wrong and wrongdoer that commits to mapping the epistemic and relational terrain differently. A mere diversion of attention, even for good reason, is not forgiveness, and diverting one's attention is consistent with the persistence of a perspective on the wrongdoer that is defined by her wrong that can be activated in the future. To forgive a wrong in any but a quite minimal sense requires an attempt to re-map the emotional terrain that's been affected by having been wronged. Just so for epistemic wrongs and the epistemic dimension of non-epistemic wrongs. To forgive another person on the epistemic level is to represent their merits as a potential epistemic collaborator in a way that is not dominated by the wrong they have done.

What then does resentment and the moderating of resentment look like through an epistemic lens? Resentment, we said in the previous section, functions most principally in the forgiveness literature as a proxy for a suite of negative reactive attitudes levelled principally at the wrongdoer. It is a personally invested disapproval. This disapproval guards against misplaced trust and the personal costs that can come with depending on undependable people. Clearly, it is possible to harbor resentment towards another person qua epistemic agent. ${ }^{20}$ Just as resentment in general fixes one's attention on

\footnotetext{
${ }^{20}$ One might think not. For example, Dougherty (2010) has argued that charges like "you should have known better" reduce to prudential or moral failings. McCormick (2021) claims that one can violate one's epistemic duties without being worthy of blame and can be an apt target of blame for a belief despite having met relevant epistemic standards. Blaming someone for "believing badly" should not be explained in terms of a person being worthy of blame for violating epistemic duties that float free from the ethical domain. One can violate an epistemic duty without being an apt target of blame. Kauppinen (2018) argues that epistemic accountability does not involve blame or resentment but merely downgrading one's epistemic trust in another person. The appearance of conflict here is, I think, illusory. Resentment is an important but amphibolous term. I am, once again, using it in a general way as covering a suite of reactive attitudes that express a personally invested disapproval of another person. I am not here claiming that the disapproving needs to be uniquely or autonomously epistemic. The object of disapproval can be distinctly epistemic in nature or include epistemic dimensions whether or not the attitude directed towards that object is uniquely epistemic or not. This does not contradict Dougherty or McCormick, so I pass over their arguments without further comment here. As for Kauppinen, if the claim is that there is no form of blame or resentment that can take
} 
reasons not to easily trust another person, so epistemic resentment fixes one's cognitive and affective attention on reasons to downgrade or eliminate one's epistemic dependence on the wrongdoer or people like the wrongdoer.

Specifically epistemic resentment of the wrongdoer might take many forms. Martin now finds it easy to give a negative appraisal of Madeleine's sincerity as a testifier. Martin feels alienated from the goals and values which shape Madeleine's epistemic interests. Maya acquires a vested interest in down-grading Miles' competence and might enjoy a little schadenfreude if he endured a public silencing of his own. She acquires a wariness of Miles' sensitivity to defeaters such that even if Miles testifies on a matter within his competence, Maya does not feel confident that he has recognized all the relevant higherorder evidence because his biases might have insulated his perspective. Maria might feel repulsed by the way that Mona's action shows a willingness to let selfish interests, by Maria's lights, encroach on her epistemic behavior. Maria might suspect that Mona's ability to rationalize her behavior implies that she is prone to self-deception. And, of course, all of the above is reason for Martin, Maria, and Maya to be less inclined to treat their epistemic others as peers when they disagree, not because they have discovered their respective wrongdoers to be incompetent per se but simply because treating someone as an epistemic peer often requires a great deal of epistemic trust.

To moderate one's distinctively epistemic resentment and renegotiate blame in an act of forgiveness, the victim must reject the centrality of the wrong as a lens for viewing the desirability of epistemic dependence on and collaboration with the wrongdoer. This affects the moderation of, but not necessarily the elimination of, epistemic resentment towards the other person. In its place, forgiveness requires an increased openness to the wrongdoer demonstrating that they can be worthy of epistemic trust. ${ }^{21}$ The specific means of moderating one's resentment can be various but will need to address both the epistemic and the moral level. It is a truism of the testimony literature that trusting a testifier requires being able to trust not just the testifier's competence but also her sincerity. Just so, repairing epistemic trust across the diverse ways in which one can partner with another person is not a matter of simply restoring one's faith in the cognitive horsepower of the other, though it may involve that. One's faith in their goodwill, sincerity, and attention matter too.

As with forgiveness in general, one might moderate one's epistemic resentment by actively being mindful of mitigating circumstances, of the positive qualities of the other person, of one's own failings, of the sincerity of their contrition, or of the ways they have made changes in their life for the better. One might plan for ways of expressing one's emotions that have less potential to damage the relationship or to overstep the bounds of what counts as a reasonable reaction and so on. The over-arching point, however, is that, akin to the way one might adopt a mental frame to facilitate a "seeing as," just so forgiveness requires an implicit recognition and repudiation of

an object that is epistemic in nature or has epistemic dimensions, then I simply deny the claim, and I think the cases I have provided in the paper are clear counterexamples. I think it is more plausible, however, to gloss the paper as claiming that to the extent that there is a distinct form of epistemic accountability that does not infringe on the ethical domain one does not need to invoke blame or resentment to characterize it. That would be some reason to think that there is a kind of epistemic failing that is not a candidate for forgiveness. Nothing in this paper, however, hangs on the truth or falsity of that claim, and thus I will not comment further here on this argument either.

${ }^{21}$ Given the emphasis in my essay on the lens through which one represents one's relationship with a wrongdoer, the following from Jones' (1996) essay on trust is noteworthy. "[T]he claim being advanced here is that the attitude of optimism constitutive of trust is a distinctive way of seeing another. This way of seeing the other is constituted by a distinctive trusting cognitive set, which makes one's willingness to rely on the other seem reasonable" (1996: 11). 
the way a wrong can provide a mental frame that defines one's relationship with the wrongdoer, including one's relationship to the wrongdoer as a knower. "Seeing as" can, of course, occur independent of one's agency. One can, however, facilitate it by choosing to be mindful of certain pieces of background information rather than others, of recalling some episodes rather than others, of fixing on some aspects of a scene rather than others, and so on. Alternatively, one might simply seek to recognize and disengage from ways of allocating one's attention or interpreting behavior that are dominated by a prior "seeing as" with which one is seeking not to identify.

Just as with forgiveness in general, there are relevantly different cases that shape how epistemic blame should be renegotiated. One is when the wrongdoer owns his or her blame, for example, by apologizing. When Miles apologizes to Maya, he owns that he has wronged Maya in committing an epistemic injustice against her and pledges to make relevant changes. If Maya chooses to forgive him, one natural way that relating differently to blame might look for her is to use his apology as the relevant lens through which to see their relationship and thus their future epistemic collaborations. Rather than simply expunging the wrong from her memory, using the apology itself as the relevant lens honors the relevance of the wrong to their relationship while nesting it within a good faith acceptance of his contrition and an openness to his making good on his commitment to change. Instead of simply writing off Miles as someone likely to commit more epistemic injustices, Maya could instead choose, in accepting his apology, to see him as someone who is now more capable of relating well to her for having repented of an act he recognizes as having harmed her as a knower. ${ }^{22}$

What, though, of the case where the wrongdoer does not apologize? Again, there is a relevant distinction to be made. Suppose the wrongdoer's track-record and current trajectory is such that it is open to the victim to view them as someone who is becoming or already is a person who is worthy of more epistemic trust than the wrong committed would imply on its own. In that case, the victim might take that fact as reason to adopt the same stance towards the wrongdoer that they would adopt in the face of a good faith apology. For example, suppose that though Madeleine confessed that she had the affair, she did not present it as a wrong committed against Martin, and thus, Martin does not feel like she owned any guilt or took on blame for the way she hurt him. Yet, over time, Madeline shows by her actions a newfound commitment to the relationship, and Martin is able to open himself to trusting her more, both epistemically and otherwise. Though sometimes tempted to see an ambiguous action through the lens of the past relational rupture, Martin chooses to prioritize her track-record since the relational rupture as the relevant lens and in so doing enacts a forgiving stance towards her vis-à-vis the affair.

Our social norms do not pressure us to apologize for our epistemic wrongs as frequently as for other kinds of wrong, at least not as yet. Moreover, when we do so apologize, our norms are often satisfied without the demonstration of strong emotion and thus without a "costly signal" that helps us discern when an apology for an epistemic wrong should be accepted. Thus, one might think that adopting a forgiving stance towards an epistemic wrong based on one's assessment of the overall character and characterological trajectory of another person may be especially important for us, perhaps more important than it is for non-epistemic wrongs.

We are left, of course, with the case of the wrongdoer who provides no behavioral clue as to their worthiness for renewed epistemic trust. Indeed, they may give cause

\footnotetext{
${ }^{22} \mathrm{I}$ am not, of course, assuming that Maya is obligated to forgive Miles but rather describing what it would mean to extend forgiveness in this situation. As with forgiveness in general, there may be cases of epistemic forgiveness in which many would feel that one should not forgive even a contrite wrongdoer.
} 
the other way. Suppose, for example, that Mona not only does not admit her wrong to Marie but bristles in their interactions, allowing the same psychological dynamics that led Mona to lie to her sister to poison their interactions in their time of bereavement. Mona is not a reliable or just testifier in such a state and to avoid having to tell the truth about what happened with their mother, Mona continues to lie and evade. Does it make any sense to speak of forgiveness here, epistemic or otherwise? It is not hard to imagine something like the following. Even though Marie does not take Mona to have owned her guilt and even though the wrong done is indicative of Mona's past and continuing character, Marie might nonetheless adopt a compassionate frame in how she thinks of Mona. She might, for instance, choose not to let the fact that she feels wounded by Mona's actions act as the frame through which she views Mona but instead effortfully foreground in her mind the ways in which Mona's actions themselves come from a wounded place and do not damage the reservoirs of competence and goodwill that Mona is capable of displaying in other situations. This allows Marie to hold onto the fact that Mona is worthy of epistemic trust on many occasions and that it is reasonable for her to hope that epistemic cooperation with Mona in the future is worth investing in now.

Moreover, one might think that forgiveness in general is helpful to one's life as a knower quite apart from the state of the wrongdoer. Marie, for example, might recognize that adopting a cognitive-affective stance towards Mona that foregrounds the wrongs Marie has suffered would have a jaundicing effect on Marie's own outlook that Marie does not want for herself. She may not want it for herself in part for an epistemic reason, namely, that allowing a wrong to be the lens through which she sees the world would damage her ability to represent that world fairly. Unforgiveness is an obstacle to knowledge. The result, if it is not an act of forgiveness, must at least be acknowledged as a forgiving outlook that predisposes Marie to hold up her end if an opportunity for reconciliation with Mona arises.

Highlighting the interactions of forgiveness with the epistemic is partly important because repair is an essential activity for social knowers. Anyone that one epistemically relies on is someone that sometimes commits epistemic wrongs and wrongs that have epistemic implications. The overlap of forgiveness and the epistemic is also important for understanding forgiveness itself. It is easy to fall short of full forgiveness by neglecting the epistemic. The first and most obvious reason why this might happen is that it is comparatively easy for an epistemic wrong to escape notice, especially for the perpetrator of one. That is not to say that epistemic wrongs are not keenly felt by the victim, but it was only relatively recently that epistemic injustice, for example, became a mainstream category in philosophy. The material imprint of a wrong in the world can be hard to deny, likewise the voicing of hurtful words. The damaging of epistemic trust often comes with both but is subtly in the background.

Second, an easy way for forgiveness to fall short is for a discrepancy to arise between the forgiving of an act and the forgiving of the person. One might, for instance, forswear taking vengeance or demanding restitution for a wrong. One may pledge, to oneself if not to others, not to dwell on the particular episode or bring it up again. One may be fully convinced within one's own mind that one has forgiven the wrong, and yet, represent the character of the other person moving forward in a way that has been definitively altered by the wrong done. In effect, one is holding the wrong against the wrongdoer in the way one represents the character of the other person, which in turn influences one's future interactions and the possibility of reconciliation. Moreover, even if one is live to the possibility of holding onto a wrong in how one represents the character of the other person, one is more likely to spot the relevance of moral than of epistemic character. After all, we commit wrongs qua moral agents, but one cannot divorce the moral and epistemic quite so neatly. 
Finally, as concerns one's expectations of others not directly involved in the incident, it is again easy to not notice the way a wrong might color one's perspective. If a bad relationship causes one to expect one's next partner to betray one, then one has been harmed epistemically because one's way of representing the world has been poisoned. One has become less reliable in an important range of beliefs. Even when a jaundiced representation of the world ends up being accurate, a wound-dictated detection of bad actors is not likely to be reliable in the sense of a "sensitive" belief, a belief such that if it had been false, one would not have formed it.

Another way in which a lack of forgiveness can cause harm to one's future interactions, though, is by making one more hesitant to engage in epistemic trust in new situations. This damaging of one's willingness to trust need not take the form of an inability to trust. It can take the form of affecting one's risk-taking thresholds, effectively turning situations where trust should be easy into the equivalent of high stakes situations in which trust is hard to earn and act on. ${ }^{23}$ Consider, for instance, that if Miles personally sees to it that restitution is made to Maya by way of actively attempting to facilitate her inclusion in social networks that Miles inhabits, the epistemic injustice committed against Maya might still make it harder for her to use them effectively because of the effect of the wrong at issue on her capacity to exercise epistemic trust. Even in the presence of maximally cooperative and penitent partners, epistemic forgiveness for Maya might be crucial not just for her future interactions with Miles but for Maya's exercise of her epistemic agency in general. Thus, Maya might have a reason to embrace a forgiving way of relating to Miles that is at least partly independent of how worthy he is or is not of being forgiven.

Thus, we see that far from being a curious extension of the concept of forgiveness, epistemic forgiveness is actually central to forgiveness in general. Being wronged pushes one in the direction of epistemic distrust, both when the wrong at issue is distinctively epistemic and when it is not. Joint action and the sharing of a common life have an epistemic dimension to them, and epistemic distrust presents a formidable obstacle to their achievement. Yet, a forgiveness that makes possible neither joint action nor the intimacy of a shared life brings forth a rather shabby sort of reconciliation.

In this essay, I have shown that acts of forgiveness in general have epistemic implications and that the forgiveness of epistemic wrongs is important in its own right. To be a social knower, one must not only identify experts, reason with peers, and avoid bad actors. One must engage in the hard work of repair - owning blame, moderating resentment, negotiating reconciliation. The social knower cannot skip repair. This is not because we cannot do without a few brilliant misanthropes and thus must forgive a class of people we would prefer to cut off. Rather, though not all wrongs are equal, the people we depend on individually, in groups, and through institutions are going to disappoint us morally and epistemically, and we will damage the trust of others in turn. We are fallible. Without the ability to repair trust and the frequent exercise of that ability, our common life, including our epistemic lives, will be severely impoverished. Forgiving and knowing, at least for us, are deeply intertwined. ${ }^{24}$

\footnotetext{
${ }^{23}$ Consider Buchak's work incorporating attitudes towards risk into calculations of expected utility. Two rational actors who are otherwise identical in terms of their prior probabilities and preferences might nonetheless come to different decisions based on their attitude towards risk (cf. Buchak 2013). Therefore, if one is acted on by another person so as to be influenced towards a more risk-avoidant strategy in a domain, the other person can thereby change what it is subjectively rational for one to choose.

${ }^{24}$ I would like to thank Sanford Goldberg, Brandon Fitelson, and the participants of the Social (Distance) Epistemology Series where this paper was workshopped.
} 


\section{References}

Barker S., Crerar C. and Goetze T. (2018). 'Harms and Wrongs in Epistemic Practice.' Royal Institute of Philosophy Supplements 84, 1-21.

Boult C. (2020). 'There is a Distinctively Epistemic Kind of Blame.' Philosophy and Phenomenological Research. https://doi.org/10.1111/phpr.12726.

Brown J. (2020). 'What is Epistemic Blame?' Noûs 54, 389-407.

Buchak L. (2013). Risk and Rationality. New York, NY: Oxford University Press.

Byerly T.R. (Forthcoming). Intellectual Dependability: A Virtue Theory of the Epistemic and Educational Ideal. New York, NY: Routledge.

Dotson K. (2011). 'Tracking Epistemic Violence, Tracking Practices of Silencing.' Hypatia 26, 236-57.

Dougherty T. (2010). 'Reducing Responsibility: An Evidentialist Account of Epistemic Blame.' European Journal of Philosophy 20, 534-47.

Faulkner P. (2007). On Telling and Trusting, Mind 116, 875-902.

Fricker M. (2007). Epistemic Injustice: Power and the Ethics of Knowing. New York, NY: Oxford University Press.

Fricker M. (2016). 'What's the Point of Blame? A Paradigm Based Explanation.' Noûs 50(1), 165-83.

Fricker M. (2018). 'Ambivalence About Forgiveness.' Royal Institute of Philosophy Supplements 84, 161-85.

Greco D. (2019). 'Justifications and Excuses in Epistemology.' Noûs. doi: 10.1111/nous.12309.

Green A. (2014). 'Monitoring, Testimony, and a Challenge from Social Psychology.' American Philosophical Quarterly 51, 27-38.

Griswold C. (2007). Forgiveness: A Philosophical Exploration. New York, NY: Cambridge University Press.

Hieronymi P. (2001). 'Articulating an Uncompromising Forgiveness.' Philosophy and Phenomenological Research 62, 529-55.

Hieronymi P. (2008). 'The Reasons of Trust.' Australasian Journal of Philosophy 86, 213-36.

Hughes P. (2001). 'Moral Atrocity and Political Reconciliation: A Preliminary Analysis.' International Journal of Applied Philosophy 15, 123-33.

Hughes P. and Warmke B. (2017). Forgiveness. In E.N. Zalta (ed.), Stanford Encyclopedia of Philosophy. https://plato.stanford.edu/archives/sum2017/entries/forgiveness/.

Jones K. (1996). 'Trust as an Affective Attitude.' Ethics 107, 4-25.

Kauppinen A. (2018). 'Epistemic Norms and Epistemic Accountability.' Philosopher's Imprint 18, 1-16.

Littlejohn C. (Forthcoming). 'A Plea for Epistemic Excuses.' In F. Dorsch and J. Dutant (eds), The New Evil Demon. New York, NY: Oxford University Press.

Machlachlan A. (2008). 'Forgiveness and Moral Solidarity.' In S. Bloch-Shulman and D. White (eds), Forgiveness: Probing the Boundaries. e-book [978-1-904710-62-2]. Oxford: Inter-Disciplinary Press.

McCaw B. (2015). 'The Nature of Epistemic Trust.' Social Epistemology 29, 413-30.

McCormick M. (2011). 'Taking Control of Belief.' Philosophical Investigations 14, 169-83.

McCormick M. (2021). 'Believing Badly: Doxastic Duties are not Epistemic Duties.' In K. McCain and S. Stapleford (eds), Epistemic Duties: New Arguments, New Angles, pp. 29-43. New York, NY: Routledge.

Murphy J. (1982). 'Forgiveness and Resentment.' Midwest Studies in Philosophy 7, 503-16.

Nottleman N. (2010). Blameworthy Belief: A Study in Epistemic Deontologism. Dordrecht: Springer.

Pettigrove G. (2007). 'Understanding, Excusing, Forgiving.' Philosophy and Phenomenological Research 74, $156-75$.

Rettler L. (2017). 'In Defense of Doxastic Blame.' Synthese 195, 2205-26.

Richards N. (1988). 'Forgiveness.' Ethics 99, 77-97.

Roberts R. (1995). 'Forgivingness.' American Philosophical Quarterly 32, 289-306.

Scanlon T. (2008). Moral Dimensions: Permissibility, Meaning, Blame. Cambridge, MA: Belknap/Harvard University Press.

Strawson P. (1968). 'Freedom and Resentment.' In P. Strawson (ed.), Studies in the Philosophy of Thought and Action, pp. 71-96. New York, NY: Oxford University Press.

Urban Walker M. (2013). 'Third Parties and the Social Scaffolding of Forgiveness.' Journal of Religious Ethics 41, 495-512.

Warmke B. (2016). 'The Normative Significance of Forgiveness.' Australasian Journal of Philosophy 94, 687-703.

Wettstein H. (2010). 'Forgiveness and Moral Reckoning.' Philosophia 38, 445-55.

Wolterstorff N. (2011). 'Does Forgiveness Violate Justice?' Ars Disputandi 5, 9-30.

Wolterstorff N. (2013). 'Is it Possible and Sometimes Desirable for States to Forgive?' Journal of Religious Ethics 41, 417-34. 
Wright D. (2019). 'Why Forgiving the Unrepentant is not Demeaning or Insulting: A Reply to Wolterstorff.' In G. Bock (ed.), The Philosophy of Forgiveness, Vol. IV: Christian Perspectives on Forgiveness, pp. 47-58. Wilmington, DE: Vernon Press.

Adam Green is an Associate Professor of Philosophy and a Fellow at the Institute for Human Flourishing at the University of Oklahoma.

Cite this article: Green A (2021). Forgiveness and the Repairing of Epistemic Trust. Episteme 1-17. https:// doi.org/10.1017/epi.2021.27 